\title{
Compound nouns do not always fulfill the conjunction thesis: An analysis using the mental model
} theory ${ }^{1}$

Miguel López-Astorga®i Universidad de Talca

Talca, Chile

\begin{abstract}
This paper is intended to show that the properties classical logic attributes to conjunction are not always found in real compound nouns in natural language. This fact is described by means of several examples taken from different natural languages. The main conclusion is that perhaps a better option to understand human language and communicative phenomena is to assume a basically semantic approach with the mental model theory proposed as a more suitable alternative. This is because the fact that the logical properties that are not always present in real compound nouns is not considered a problem under the framework of this theory.
\end{abstract}

Key words: compound noun; conjunction; mental model; semantics; syntax.

\section{Resumen}

Los nombres compuestos no cumplen siempre la tesis de la conjunción: Un análisis desde la teoría de los modelos mentales

Este trabajo intenta mostrar que las propiedades que la lógica clásica atribuye a la conjunción no se pueden siempre encontrar en nombres compuestos reales en lenguaje natural. Este hecho es descrito por medio de varios ejemplos y recurriendo a diferentes lenguajes naturales. Las conclusiones son que, quizás, una mejor opción para comprender el lenguaje humano y los fenómenos comunicativos puede ser asumir un enfoque básicamente semántico, y que una buena alternativa en este sentido puede ser la teoría de los modelos mentales. Esto es así porque los problemas

\footnotetext{
${ }^{1}$ This paper is a result of the Project CONICYT/FONDECYT/REGULAR/FOLIO № 1180013, “Recuperación de las formas lógicas de los enunciados a partir de un análisis de las posibilidades semánticas a las que hacen referencia", supported by the National Fund for Scientific and Technological Development (FONDECYT, according to its initials in Spanish), Government of Chile.
} 
provocados por las propiedades lógicas que no están a veces presentes en nombres compuestos reales no son verdaderas dificultades bajo el marco de esa teoría.

Palabras clave: nombre compuesto; conjunción; modelo mental; semántica; sintaxis.

\section{Résumé}

Les noms composés ne sont pas toujours conformes à la thèse de conjonction : Une analyse de la théorie des modèles mentaux

Cet article est destiné à montrer que les propriétés que la logique classique attribue à la conjonction ne se trouvent pas toujours dans les noms composés réels en langage naturel. Ce fait est décrit au moyen de plusieurs exemples et en faisant appel à des langues naturelles différentes. En conclusion, une meilleure option pour comprendre le langage humain et les phénomènes de communication pourrait être d'adopter une approche fondamentalement sémantique. De même, une bonne alternative dans ce sens peut être la théorie des modèles mentaux. Ceci s'explique parce que les problèmes causés par les propriétés logiques qui ne sont pas parfois présentes dans les noms composés réels, ne sont pas des difficultés réelles dans le cadre de cette théorie.

Mots-clés : nom composé ; conjonction ; modèle mental ; sémantique ; syntaxe. 


\section{SOBRE EL AUTOR}

\section{Miguel López-Astorga}

Profesor Titular, Instituto de Estudios Humanísticos "Juan Ignacio Molina", Universidad de Talca, Campus de Talca (Chile). Doctor en Lógica y Filosofía de la Ciencia. Áreas de investigación: Filosofía del Lenguaje, Filosofía de la Ciencia Cognitiva, Epistemología.

Correo electrónico: milopez@utalca.cl

\section{CÓMO CITAR ESTE ARTÍCULO}

López-Astorga, M. (2021). Compound nouns do not always fulfill the conjunction thesis: An analysis using the mental model theory. Lenguaje, 49(2), 484-496. https://doi.org/10.25100/lenguaje.v49i2.9365. 


\section{INTRODUCTION}

The general idea that a logic of some kind underlies language is to be found in many theories, including both cognitive and linguistic frameworks. Some examples that support this idea can be seen in the arguments raised in papers such as that of Henle (1962), theories such as mental logic (e.g., Braine \& O'Brien, 1998a), in studies such as that of Beth and Piaget (1966), or by accounts of government-binding theory (e.g., Chomsky, 1981). Indeed, the concept of logical form seems to be essential in such approaches, which can lead one to assume that they are linked to logic.

However, this idea can cause significant problems. This is the case, at least, if it is thought that the connectives in that underlying logic have the properties assigned to them by classical logic, and hence they are understood from a narrow logical point of view. All the classical operators appear to have difficulties in this area, especially with the conditional and disjunction (see, e.g., Orenes \& Johnson-Laird, 2012). Nevertheless, the language point that will be addressed here is conjunction.

There are multiple problems that can be observed if it is proposed that human language follows the requirements that logic imposes on conjunction. For example, as indicated in papers such as that of Johnson-Laird et al. (2015), infinite conjuncts can be joined to a conjunction as follows:

[I] $\quad \mathrm{A} \& \mathrm{~B}$

Classical logic allows, for instance, deriving B from [I] infinite times, and then joining that infinite number of propositions to [I]. The result would be akin to [II].

[II] $\quad$ A \& B \& B \& B \& B...

[II] is a problem because it can lead to an infinite process that would prevent a speaker from moving forward. For example, if ' $A$ ' were 'Today is Monday' and ' $B$ ' meant 'Today is sunny', [II] would imply that people would build a sentence such as 'Today is Monday and today is sunny and today is sunny and today is sunny and today is sunny...' The final dotted line indicates that they would never finish adding the conjunct B, or 'today is sunny'. So, individuals could not keep reasoning or speaking.

But problems such as this are usually easily removed by the aforementioned theories. For example, the mental logic theory proposes that the formal rules that enable a speaker to separate and link conjuncts are rules of a special sort. They are called 'Feeder Schemata'. According to the theory, they are used only when necessary, which prevents concluding formulae such as [II] (see, e.g., Braine \& O’Brien, 1998b).

Nonetheless, there is a problem related to conjunction that is truly difficult to solve when it is considered that natural language follows the logical properties of this connective. That problem is linked to the conjunction thesis (see, e.g., RodríguezPereyra, 2006, 2009). It is present, for instance, when it is taken into account that compound nouns can be, from a logical perspective, essentially conjunctions: when it 
is assumed that compound nouns can refer to underlying sentences linking their nouns.

This paper intends to present this specific problem in detail and to offer a possible solution. The solution proposes the idea of rejecting the prominence of logic in language and evolving instead towards more semantic (in the sense of the word in linguistics) positions. Thereby, the first section will delve deeper into what the logical conjunction really is, and outline its properties. The second section will give some examples of compound nouns whose underlying conjunctions of sentences seem not to follow one of the most important characteristics of conjunction: the aforementioned conjunction thesis (this point will also be illustrated using expressions found in languages other than English - in particular, Spanish and Portuguese - which will make it evident that the difficulties are not specific to English). Then, a contemporary basically semantic cognitive and linguistic framework will be described. The framework will be that of the mental model theory (e.g., Khemlani et al., 2018). Finally, this latter framework will be used to explain how problems such as that of the conjunction thesis make no sense, given the framework's tendency to remove the importance of logical form.

\section{ANALYSIS AND DISCUSSION}

\section{The logical conjunction}

In general, the way conjunction is understood under classical logic and its properties in that very logic are very easy to understand. In a truth table, a conjunction can be true only in one case: when all of its conjuncts are true as well.

Let [I] be a logical conjunction. There are then four possibilities: i) both A and $B$ are true, ii) A is true and B is not, iii) B is true and A is not, and iv) both A and B are false. So, according to this, [I] can be true only in the case of $\mathrm{i}$ ), that is, when the two conjuncts are both true.

However, this has a clear consequence which is directly related to the conjunction thesis: if [I] is true, then, necessarily, A alone or by itself and B alone or by itself have to be true too. To present the conjunction thesis, the concept of 'truthmaker' is usually used. What a truthmaker really is somewhat controversial (see, e.g, Rodríguez-Pereyra, 2006). However, it allows for a more rigorous definition of the conjunction theses. Although there are different formulations of the thesis, the basic idea is that if something is a truthmaker for [I], it also has to be a truthmaker for A alone or by itself and for B alone or by itself.

This last point appears to be obvious. However, from the so-called 'Analytic Philosophy', it has been questioned (see, e.g., Rodríguez-Pereyra, 2006, 2009). This paper will also question it. However, beyond the logical and philosophical arguments that have been put forward in the field of Analytic Philosophy, it will focus mainly on real natural language, which seems to provide numerous examples in which the conjunction thesis is not fulfilled. Of course, this fact makes it difficult to accept a logic 
related to language and message transmission in human communication. For this reason and its linguistic relevance, the next section is dedicated to the presentation of some of these examples. For the sake of simplicity, the accounts below do not resort to the concept of truthmaker. Nevertheless, it is important to keep in mind that the real definition of the conjunction thesis assumes that concept.

\section{Some examples of true conjunctions with false conjuncts}

Before considering the examples to be presented in this section, there is an important point to take into account. It can be thought that compound nouns are, in logical terms, essentially conjunctions. For instance, a case such as the following can be analyzed:

[III] Suitcase

Clearly, [III] is a compound noun and it seems to be, in its deep logical structure, a conjunction of two sentences: 'this object is to transport suits' and 'this object is a case'. This idea can seem novel. But it can be supported by experimental results which have shown that people do not appear to consider conjunction as a logical connective. Most of the time, when individuals link two propositions by means of a conjunction, they tend to think that they are only sorting data and putting different pieces of information together (Fillenbaum, 1977; see also, e.g., Braine et al., 1998). Thus, one might think that the difference between a compound noun and a conjunction of two sentences is not absolutely clear, at least from a psychological point of view.

Nonetheless, [III] is not a problem from the perspective being taken in this paper. If it is true that something is a suitcase (the conjunction), it is also true that that very object can be used to transport suits (one of the conjuncts) and that it is a case (the other conjunct). However, there are other examples of compound nouns in which this is not the case. This is especially evident, for example, in the naming of certain animals. For example:

[IV] Sea horse

As with other compound names, [IV] can be considered a logical conjunction too; in this case, linking the sentences 'this living being lives at sea' and 'this living being is a horse'. However, the difficulty now is that, while [IV] is true, only one of its conjuncts is true. Obviously, the first conjunct ('this living being lives at sea') can be considered to be true, since, ultimately, a sea horse is an animal that needs the sea to live and, therefore, lives at sea. Nevertheless, 'this living being is a horse' is a problem, as a sea horse is not, as is well known, a horse, but a fish. Accordingly, it can be claimed that [IV] contravenes the conjunction thesis because, whenever the conjunction in its entirety is true, one of its conjuncts, ('this living being is a horse'), is not.

And this problem does not only occur in English. The translation of [IV], for example, into Spanish is: 
$\left[\mathrm{IV}^{\mathrm{s}}\right]$ Caballo de mar

And into Portuguese is:

[IVp] Cavalo marinho

In both cases, the situation is akin to that in English. [IV s] is also the union of two sentences: 'este ser vivo es un caballo' ('this living being is a horse') and 'este ser vivo vive en el mar' ('this living being lives at sea'). On the other hand, exactly the same happens with [IVp], its two sentences being identical: 'este ser vivo é um cavalo' ('this living being is a horse') and 'este ser vivo vive no mar' ('this living being lives at sea'). Hence, both in $\left[\mathrm{IV}^{\mathrm{s}}\right]$ and in $\left[\mathrm{IVP}^{\mathrm{p}}\right]$ the same problem exists: whenever the conjunction is true, one of its conjuncts ('este ser vivo es un caballo' in [IV'] and 'este ser vivo é um cavalo' in [IVp]) is false.

Furthermore, [IV] (and [IV $]$ and [IVp]) is not an isolated example or an exception. Another example of a problematic compound noun is the name of another animal:

[V] Starfish

The two sentences here are clearly 'this is a star' and 'this is a fish'. Following the conjunction thesis, this means that, if [V] is true, the conjunct 'this is a star' and the conjunct 'this is a fish' must be so as well. However, that is not the case. A starfish is neither a star nor a fish. Accordingly, it can be stated that the problem with [V] is even greater, as, when it is true, neither of its conjuncts is true.

The difficulty in languages such as Spanish or Portuguese is of a lesser degree. In these, the problem is closer to that of [IV], because only one of the conjuncts is false when the conjunction is true. The translations of [V] into those languages are:

$\left[\mathrm{V}^{\mathrm{s}}\right] \quad$ Estrella de mar

$[\mathrm{Vp}] \quad$ Estrela do mar

The second conjunct in both cases ('este ser vivo vive en el mar' in Spanish and 'Este ser vivo vive no mar' in Portuguese) does not cause difficulties. In both languages it means 'this living being lives at sea'. The first conjunct is the real difficulty here: the meaning of both 'estrella' and 'estrela' is 'star', and, as stated, a starfish is not a star.

However, this does not remove the problem. The problem continues to be, as stated, the same as that of [IV]. Based on the conjunction thesis, the two conjuncts should be true when the conjunction in its entirety is true, not just one of them. Furthermore, even if the problem were only in one natural language between the known languages, it would continue to be an issue. If the idea is that logic underlies human language and communication, it is enough that it is not the case in just one 
particular natural language to refute the idea. The rules and principles of logic should be followed in any language being used, not only in some or in most of them.

Thus, from this point of view, the cases of some particular translations do not have any influence on these arguments either. There are names of animals that are not necessarily controversial from this perspective in English, but they are in other languages. For example,

\section{[VI] Anteater}

In English, there is no difficulty with [VI]. It refers to an animal that eats (one of the conjuncts) ants (the other conjunct). However, that is different in other languages. In Portuguese, 'anteater' is not a compound noun:

[VIp] Tamanduá

But, in Spanish, the problem of the conjunction thesis appears again, as the translation is as follows:

$\left[\mathrm{VI}^{\mathrm{s}}\right]$ Oso hormiguero

It can be said that [VI'] has two conjuncts: 'este animal es un oso' ('this animal is a bear') and 'este animal come hormigas' ('this animal eats ants'). Given that it eats ants, the second conjunct does not cause difficulties. However, the first conjunct makes the name contrary to the conjunction thesis, since an anteater is not a bear.

Of course, one might think that 'anteater' could also be said, for example, in English 'ant bear' and in Portuguese 'urso' ('bear') 'de formiga' ('related to ant'). Nevertheless, [ $\left.\mathrm{VI}^{\mathrm{s}}\right]$, which is the name most commonly used in Spanish, is already by itself another problem for the theories linking logic and logical form to language. But all of these problems seem to disappear if a basically semantic approach is applied. This approach is the mental model theory and it is outlined in more detail in the next section.

\section{Iconicity and the mental model theory}

There are numerous studies which explain the central theses of the mental model theory. Its proponents have also improved it over the years resulting in current versions being distinct from earlier ones. However, some recent studies that can perhaps be considered representative are those of Johnson-Laird (2012, 2015), Johnson-Laird et al. (2015), Khemlani et al. (2018), Khemlani et al. (2017), and Orenes and Johnson-Laird (2012). The theory is complex and addresses many aspects of knowledge, reasoning, and language. For this last reason, this section will only consider the main points related to the objectives of this paper.

It can be said that a key concept of the theory is iconicity. Given an expression in natural language, people tend to build iconic images of the semantic possibilities that could exist if the expression were true. For example, from a conditional such as: 
[VII] If I go to the cinema, I will buy a can of soda

Individuals can construct three possible iconic pictures of three possibilities in the world:

[VIII] I go to the cinema \& I buy a can of soda

[IX] I do not go to the cinema \& I buy a can of soda

[X] I do not go to the cinema \& I do not buy a can of soda

Evidently, the only possibility that cannot be true if [VII] is as stated is that I go to the cinema and I do not buy a can of soda (the antecedent of the conditional would be true and the consequent false). Hence, [VIII], [IX], and [X] iconically represent all the situations in the world that are possible if [VII] is true. Nonetheless, in principle, they have nothing to do with logic or syntactic structures. The mental model theory does not propose that, given a conditional with a structure such as that of [VII], people will always tend to think about three possibilities with structures such as those of [VIII], [IX], and [X]. The context, pragmatics, and, above all, semantics and the meaning of the words used in the expressions can make the possibilities different. That can be clearly seen by means of this example:

[XI] “(...) if Fanny travelled by public transport then she didn't travel by tram (...)" (Orenes \& Johnson-Laird, 2012, p. 375).

There is no doubt that $[\mathrm{XI}]$ is a conditional. However, it is also clear that the possibilities iconically representing the world that would correspond to it if it were true are not three, but two:

[XII] Fanny travels by public transport \& Fanny does not travel by tram [XIII] Fanny does not travel by public transport \& Fanny does not travel by tram

As the possibilities associated with the sentence are, as indicated, iconic images that can be true if the particular sentence is true too, it is evident that the other two combinations cannot be considered here. If [XI] is true, it cannot be stated that Fanny travelled by public transport and she travelled by tram (again, the antecedent of the conditional would be true and its consequent false). But, at the same time, it cannot be true either that Fanny did not travel by public transport and she travelled by tram since the tram is a form of public transport.

So, as claimed, the foundation of the theory is that, given an expression in natural language, people often think only about the iconic pictures of the world directly related to it that can be derived as possibilities if the expression is true. As it can be checked, there is not a direct relationship to syntax, and this can solve the problem of the conjunction thesis outlined above. The next section shows how. 


\section{The mental model theory and the conjunction thesis}

That the rejection of the conjunction thesis can be related to semantics has already been proposed (e.g., López-Astorga, 2010). Nevertheless, the purpose of this paper is to argue that the cause of that rejection can lie in cognitive processes akin to those described by the mental model theory.

Under this latter theory, a compound noun such as [IV] is not necessarily a logical conjunction with its properties. If individuals deem [IV] as true, they do not think of it as a logical sentence. It only leads them to build an iconic picture of the animal, which can be the result of a process such as the following.

Given the statement that [IV] (or, for example, [IV $\left.{ }^{\mathrm{s}}\right]$ or [IVp]) is true, in principle, two elements, 'sea' and 'horse', could be combined. The possible combinations would be these ones:

[XIV] Sea \& horse

[XV] Sea \& not-horse

[XVI] Not-sea \& horse

[XVII] Not-sea \& not-horse

But it is evident that individuals would only pay attention to the first of these combinations, since, if it is true that there is a sea horse, the two elements ('sea' and 'horse') have to be present, whereas in [XV] 'horse' is missing, in [XVI] 'sea' is missing, and in [XVII] both 'sea' and 'horse' are missing. Accordingly, if [IV] is true, it is only possible to think about [XIV]. This means, on the one hand, that the two elements of the compound noun cannot be separated and always have to be together. On the other hand, it also indicates that, therefore, only an iconic image containing the element 'sea' and the element 'horse' at once can be constructed. This necessarily leads to the correct animal, that is, a sea horse, and not to a completely different animal such as a horse (a situation that would be the result of considering just one of the elements).

In this way, the conjunction thesis problem disappears. The difficulty only exists if human language is considered to be based on logic. If compound nouns are not deemed as conjunctions of two conjuncts, but as semantic descriptors that refer to a particular reality (in this case, a sea horse) and whose parts cannot be divided (because, if separated, they denote different realities), the problem does not even make sense. From the framework of the mental model theory, 'sea', 'horse' and 'sea horse' refer to three entirely different entities because they lead to three entirely different iconic pictures. They are hence three linguistic expressions each with different meanings. The meaning of the third is not the result of the sum of the meanings of the first two, and this is because the third leads to an iconic image that is not the sum of the iconic images of the first two.

It is evident that this also applies to cases such as those of [V] or [VIs]. A semantic approach such as that of the mental model theory sees language not as a construction of pieces that fit because they fulfill logic rules and principles, but as a 
set of expressions that enable thinking about reality in an iconic way. Thus, it can be very enlightening to remind ourselves that [VI] in English and [VI $\left.{ }^{\mathrm{s}}\right]$ in Spanish are linked to the same iconic picture. Theoretically, [VIs] should cause difficulties (since it refers to the concept of the bear). Nevertheless, neither [VI] nor [VIs] appear to create problems in everyday conversations. The reason could be, as stated, that despite the compound form of the words, they are in fact related to exactly the same iconic representation.

\section{The potential of the mental model theory}

Accordingly, it seems that there is no doubt that the mental model theory has great potential in understanding the true nature of language and human communication. The literature (see, e.g., most of the studies cited in this paper) demonstrates that it is such a strong theory it is able to solve many problems and puzzles related to typical responses given by participants in reasoning tasks (responses which are often unusual or, at least, unexpected from the logical point of view). However, arguments such as those mentioned above follow similar lines to those in papers such as, for example, that of López-Astorga (2019), which also shows what the theory can offer in fields such as linguistics.

Furthermore, a clear advantage of the theory is that, although it is mainly semantic, it is not necessarily incompatible with pragmatics and syntax. As highlighted in papers such as Orenes and Johnson-Laird (2012), pragmatics is essential in the theory, too. In fact, it can modify, change, remove, and qualify the iconic images people build. As far as syntax is concerned, it is evident that the processes of combining possibilities imply a syntax of some kind to relate the iconic pictures, even if that syntax is minimal. In addition, studies such as that by López-Astorga (2017) reveal that it is even possible to recover syntactic forms from iconic possibilities such as those from the mental model theory.

So, it appears that it is worth continuing to explore the resources the mental model theory can provide to understand and analyze both language and the human communicative reality. From what has been presented in this paper, one hopes that the theory will help solve linguistic problems that arise today and for which there are no agreed solutions. However, even if this is not the case, it can be still interesting to assume the theory as a provisional explanatory framework in order to determine the extent to which it can remove difficulties related to issues such as that of compound nouns discussed here.

\section{CONCLUSIONS}

It is hard to accept that there is a logic linked to natural human language. This is especially difficult if it is also assumed that that logic has the same characteristics as classical logic. The specialist literature demonstrates that the conditional, disjunction, and conjunction all have problems in this regard. 
This paper has addressed the particular case of conjunction with its purpose to argue in favor of the idea that this connective does not always work in language as expected under classical logic. Under this logic, if a conjunction is true, its conjuncts must also be true. It can be considered that compound nouns are, in their deep structure, conjunctions. If this is accepted, there are cases in which, while the conjunction in its entirety is true, its conjuncts are not necessarily that. The paper has presented examples of these in different languages (English, Spanish, and Portuguese).

The basic proposal is that if logic is ignored and the basic theses of the mental model theory are accepted, these difficulties disappear. This theory highlights the value of semantics. It relates language to iconic images representing situations in which the sentences are true. Thus, it can explain that a compound noun can be taken as correct for a particular object or being, and that the conjuncts corresponding to that compound noun may not be attributed by themselves to that same object or being at the same time. The iconic picture may need both conjuncts to be possible. Without one of them, for example, the other may not be correct for the same reference.

Accordingly, the mental model theory presents an interesting framework to understand human language. Its approach is essentially semantic, something that cannot be forgotten. Nevertheless, as pointed out, it is not independent from pragmatics and syntax.

\section{REFERENCES}

Beth, E.W., \& Piaget, J. (1966). Mathematical Epistemology and Psychology (Trad. W. Mays). https://doi.org/10.1007/978-94-017-2193-6.

Braine, M.D.S., \& O'Brien, D.P. (Eds.) (1998a). Mental Logic. Lawrence Erlbaum Associates Publishers.

Braine, M.D.S., \& O'Brien, D.P. (1998b). The Theory of Mental-Propositional Logic: Description and Illustration. In M.D.S. Braine \& D.P. O'Brien (Eds.), Mental Logic (pp. 79-89). Lawrence Erlbaum Associates Publishers.

Braine, M.D.S., O’Brien, D.P., Noveck, I.A., Samuels, M.C., Lea, R.B., Fisch, S.M., \& Yang, Y. (1998). Further Evidence for the Theory: Predicting Intermediate and Multiple Conclusions in Propositional Logic Inference Problems. In M.D.S. Braine \& D.P. O’Brien (Eds.), Mental Logic (pp. 145-197). Lawrence Erlbaum Associates Publishers.

Chomsky, N. (1981). Lectures on Government and Binding. Foris Publications.

Fillenbaum, S. (1977). Mind your p's and q's: The role of content and context in some uses of and, or, and if. The Psychology of Learning and Motivation, 11, 41-100. https://doi.org/10.1016/S0079-7421(08)60475-2.

Henle, M. (1962). On the relation between logic and thinking. Psychological Review, 69(4), 366-378. https://doi.org/10.1037/h0042043. 
Johnson-Laird, P.N. (2012). Inference with Mental Models. In K.J. Holyoak \& R.G. Morrison (Eds.), The Oxford Handbook of Thinking and Reasoning (pp. 134-145). https://doi.org/10.1093/oxfordhb/9780199734689.001.0001.

Johnson-Laird, P.N. (2015). How to improve thinking. In R. Wegerif, L. Li \& J.C. Kaufman (Eds.), The Routledge International Handbook of Research on Teaching Thinking (pp. 80-91). Routledge.

Johnson-Laird, P.N., Khemlani, S.S., \& Goodwin, G.P. (2015). Logic, probability, and human reasoning. Trends in Cognitive Sciences, 19(4), 201-214. https://doi.org/10.1016/j.tics.2015.02.006.

Khemlani, S.S., Byrne, R.M.J., \& Johnson-Laird, P.N. (2018). Facts and Possibilities: A Model-Based Theory of Sentential Reasoning. Cognitive Science, 42(6), 1887-1924. https://doi.org/10.1111/cogs.12634.

Khemlani, S.S., Hinterecker, T., \& Johnson-Laird, P.N. (2017). The provenance of modal inference. In G. Gunzelmann, A. Howes, T. Tenbrink \& E.J. Davelaar (Eds.), Proceedings of the $39^{\text {th }}$ Annual Meeting of the Cognitive Science Society (pp. 663-668). Cognitive Science Society.

López-Astorga, M. (2010). El rechazo de la tesis de la conjunción y sus implicaciones en la teoría de la probabilidad. Paralaje, 4, 194-206.

López-Astorga, M. (2017). Mental Models are Compatible with Logical Forms. In A. López-Varela (Ed.), Interdisciplinary Approaches to Semiotics (pp. 31-42). http://doi.org/10.5772/67436.

López-Astorga, M. (2019). Language acquisition and innate cognitive abilities: An approach from the mental models theory. Círculo de Lingüística Aplicada a la Comunicación, (77), 233-242. https://doi.org/10.5209/CLAC.63286.

Orenes, I., \& Johnson-Laird, P.N. (2012). Logic, Models, and Paradoxical Inferences. Mind $\mathcal{E} \quad$ Language, 27(4), 357-377. https://doi.org/10.1111/j.14680017.2012.01448.x.

Rodríguez-Pereyra, G. (2006). Truthmaking, Entailment, and the Conjunction Thesis. Mind, 115(260), 957-982. https://doi.org/10.1093/mind/fzl957.

Rodríguez-Pereyra, G. (2009). The Disjunction and Conjunction Theses. Mind, 118(470), 427-443. https://doi.org/10.1093/mind/fzp064. 